\title{
VARIABEL EKONOMI MONETER YANG MEMPENGARUHI PERTUMBUHAN EKONOMI DAN FINANCIAL INCLUSION BANK SYARIAH DI INDONESIA PERIODE 2010-20171
}

\author{
Kholifatunahdliyah \\ Departemen Ekonomi Syariah - Fakultas Ekonomi dan Bisnis - Universitas Airlangga \\ Email: kholifatun.nahdia09@gmail.com
}

\author{
Atina Shofawati \\ Departemen Ekonomi Syariah - Fakultas Ekonomi dan Bisnis - Universitas Airlangga
} Email: atina-o@feb.unair.ac.id

\begin{abstract}
:
This study aims to determine the effect of exchange rate and money supply on economic growth and financial inclusion in Bank Syariah Period 2010-2017. The sample used is saturated samples, ie all parts of Sharia Bank, including Sharia Commercial Bank and Sharia Business Unit which in the last year of 2017 amounted to 13 Sharia Commercial Banks and 21 Sharia Business Units, furthermore this research uses time series data analysis by analyzing data from year to year. The research approach used is quantitative approach using analysis technique PLS (Partial Least Square) with four latent variables namely exchange rate and money supply as exogenous variable, economic growth as endogen intervention variable, and financial inclusion as endogen variable. The results of this study indicate: the exchange rate has a significant negative effect on economic growth, the money supply has a significant positive effect on economic growth, economic growth has a significant positive effect on financial inclusion of Sharia Bank.
\end{abstract}

Keywords: exchange rate, money supply, economic growth, and financial inclusion.

\section{PENDAHULUAN}

Sistem keuangan memegang peranan yang sangat penting dalam perekonomian. Sebagai bagian dari sistem perekonomian, sistem keuangan berfungsi mengalokasikan dana dari pihak yang mengalami surplus kepada yang mengalami defisit. Apabila sistem keuangan tidak stabil dan tidak berfungsi secara efisien, pengalokasian dana tidak akan berjalan dengan baik sehingga dapat menghambat pertumbuhan ekonomi (Bank Indonesia, 2014). Salah satu masalah sistem keuangan di Indonesia adalah akses keuangan yang tidak merata, terutama pada masyarakat menengah kebawah yang dinilai masih banyak yang belum memiliki rekening formal. Hal ini menandakan masih adanya ekslusivitas keuangan di Indonesia yang hanya bisa dirasakan oleh sebagian masyarakat berpendapatan tinggi.

Tingkat inklusi keuangan penduduk Indonesia dinilai masih kurang bila dilihat dari jumlah penduduk Indonesia yang cenderung tumbuh setiap tahunnya, dan belum banyak memiliki rekening pada institusi keuangan.

Berdasarkan data dari World Bank pada tahun 2014, penduduk dewasa Indonesia yang memiliki rekening formal (financial inclusion account) sebesar 35,9 persen. Kondisi tersebut berbeda jauh jika Indonesia dibandingkan dengan negara

\footnotetext{
${ }^{1}$ Jurnal ini merupakan bagian dari skripsi Kholifatunahdliyah, NIM: 041411431090, yang diuji pada 20 Juli 2018.
} 
Kholifatunahdliyah, et al/Jurnal Ekonomi Syariah Teori dan Terapan Vol. 6 No. 7 Juli 2019: 1395-1409; VARIABEL EKONOMI MONETER YANG MEMPENGARUHI PERTUMBUHAN EKONOMI DAN FINANCIAL INCLUSION BANK SYARIAH DI INDONESIA PERIODE 2010-2017

Malaysia, Thailand, dan Singapura yang memiliki pendapatan perkapita lebih tinggi dari Indonesia. Tingkat inklusi penduduk dewasa yang memiliki rekening formal sebesar 96,4 persen untuk Singapura, 80,7 persen untuk Malaysia, dan 78,1 persen untuk Thailand.

Inklusi keuangan memiliki tujuan untuk mengubah keuangan ekslusif menjadi inklusif, artinya semua golongan masyarakat baik masyarakat miskin, maupun kaya memiliki akses terhadap lembaga keuangan.

Berjalannya lembaga keuangan sebagai lembaga intermediari menandakan vang dapat berputar sesuai fungsinya diantara beberapa orang, dan dapat digunakan untuk pembiayaan yang produktif sehingga menggerakkan sektor riil. Hal tersebut sesuai dengan firman Allah SWT dalam Al-Quran surat Al Hasyr (59) ayat 7 berikut ini:

7. apa saja harta rampasan (fai-i) yang diberikan Allah kepada RasuINya (dari harta benda) yang berasal dari penduduk kotakota Maka adalah untuk Allah, untuk rasul, kaum kerabat, anak-anak yatim, orangorang miskin dan orang-orang yang dalam perjalanan, supaya harta itu jangan beredar di antara orang-orang Kaya saja di antara kamu. apa yang diberikan Rasul kepadamu, Maka terimalah. dan apa yang dilarangnya bagimu, Maka tinggalkanlah. dan bertakwalah kepada Allah. Sesungguhnya Allah Amat keras hukumannya.

Penelitian ini mencoba mengetahui variabel ekonomi moneter yakni nilai tukar dan jumlah uang beredar berpengaruh terhadap pertumbuhan ekonomi yang diukur melalui PDB konstan berdasarkan sektor usaha seperti sektor primer, sekunder, dan tersier dan financial inclusion yang diukur melalui jumlah kantor, jumlah rekening DPK, jumlah rekening pembiayaan, dan jumlah ATM.

Berdasarkan pendapat dari Kunt dan Klepper (2013), perekonomian dalam hal ini Produk Domestik Bruto (PDB) juga ikut berpengaruh terhadap financial inclusion perbankan. Produk Domestik Bruto merepresentasikan nilai barang dan jasa yang dihasilkan pada perekonomian suatu negara. Jika PDB meningkat, dapat dikatakan arus kegiatan ekonomi berjalan lancar. Kegiatan ekonomi yang berjalan lancar menandakan stabilitas sistem keuangan yang ditandai dengan arus uang atau barang beredar sebagaimana mestinya. Sehingga, dapat diasumsikan keuangan yang stabil menandakan sirkulasi keuangan yang baik dan juga menandakan keuangan yang inklusif.

Menurut Siregar dkk (2006), upaya untuk menstabilkan perekonomian dapat dicapai melalui kebijakan fiskal dan kebijakan moneter. Kebijakan moneter merupakan kebijakan yang bertujuan untuk menjaga kestabilan nilai rupiah. Kebijakan moneter memiliki dua sasaran akhir yakni, sasaran pada tingkat inflasi dan pada output yang dapat diukur melalui GDP. Beberapa variabel kebijakan moneter yang dapat mempengaruhi inflasi dan GDP diantaranya : suku bunga, nilai tukar, harga 
Kholifatunahdliyah, et al/Jurnal Ekonomi Syariah Teori dan Terapan Vol. 6 No. 7 Juli 2019: 1395-1409; VARIABEL EKONOMI MONETER YANG MEMPENGARUHI PERTUMBUHAN EKONOMI DAN FINANCIAL INCLUSION BANK SYARIAH DI INDONESIA PERIODE 2010-2017

aset, jumlah vang beredar, dan kredit. Pada penelitian ini mengambil dua variabel utama yang paling mempengaruhi tingkat inflasi yang nantinya akan berpengaruh pada pertumbuhan ekonomi yakni nilai tukar dan jumlah uang beredar.

Pridayanti (2012) meneliti mengenai pengaruh ekspor, impor, dan nilai tukar terhadap pertumbuhan ekonomi di Indonesia, menunjukkan hasil bahwa nilai tukar berpengaruh negatif signifikan terhadap pertumbuhan ekonomi. Selain nilai tukar, jumlah uang beredar juga mempengaruhi pertumbuhan ekonomi. Jumlah uang beredar menunjukkan daya beli suatu masyarakat. Jika jumlah uang beredar tinggi, maka hal tersebut akan membuat inflasi naik. Jika inflasi naik maka pemerintah akan menurunkan suku bunga dan hal tersebut menyebabkan pertumbuhan ekonomi akan meningkat.

Angandrowa (2008) menunjukkan bahwa jumlah vang beredar berhubungan positif terhadap pertumbuhan ekonomi Indonesia. Hal ini berarti bahwa semakin meningkat jumlah vang beredar, maka pertumbuhan ekonomi Indonesia akan semakin meningkat.

Berdasarkan uraian yang telah dijelaskan, maka rumusan masalah dalam penelitian ini adalah apakah nilai tukar berpengaruh terhadap pertumbuhan ekonomi?; apakah jumlah vang beredar berpengaruh terhadap pertumbuhan ekonomi ?; apakah pertumbuhan ekonomi berpengaruh terhadap financial inclusion Bank Syariah di Indonesia?

\section{LANDASAN TEORI}

Pengertian dan Jenis - Jenis Bank syariah

Menurut Undang-Undang Nomor 21 Tahun 2008 pasal 1 dalam Wiroso (2011:45), menyatakan bahwa perbankan syariah adalah segala sesuatu yang menyangkut Bank Syariah dan Unit Usaha Syariah, mencakup kelembagaan, kegiatan usaha, serta cara dan proses dalam melaksanakan kegiatan usahanya. Penelitian ini menggunakan objek Bank Syariah yang meliputi Bank Umum Syariah, dan Unit Usaha Syariah sesuai pendapat dari Wiroso (2011:45).

\section{Sumber Dana Bank Syariah}

Menurut Sudarsono (2003: 65-69), sumber dana bank syariah dapat diperoleh dari empat sumber, yaitu modal, titipan, investasi, dan investasi khusus dalam hal ini dinamakan Dana Pihak Ketiga (DPK). Secara sederhana, sumber dana bank syariah dapat dijelaskan sebagai berikut :

1. Al-Wadi'ah

Dari segi teknis, wadiah dapat diartikan sebagai titipan murni dari satu pihak ke pihak lain, baik individu maupun badan hukum, yang harus dijaga dan dikembalikan kapan saja si penitip kehendak.

\section{Investasi}

\section{1) Al-Mudharabah}

Dalam mengaplikasikan mudharabah, penyimpan atau deposan bertindak sebagai shahibul maal (pemilik modal) dan bank sebagai mudharib (pengelola).

2) Al-Mudharabah Mutlaqah

Penerapan mudharabah mutlaqah dapat berupa tabungan dan deposito 
Kholifatunahdliyah, et al/Jurnal Ekonomi Syariah Teori dan Terapan Vol. 6 No. 7 Juli 2019: 1395-1409; VARIABEL EKONOMI MONETER YANG MEMPENGARUHI PERTUMBUHAN EKONOMI DAN FINANCIAL INCLUSION BANK SYARIAH DI INDONESIA PERIODE 2010-2017

sehingga terdapat dua jenis himpunan dana yaitu tabungan mudharabah dan deposito mudharabah.

3. Investasi Khusus

1) Al-Mudharabah Muqayyadah on Balance Sheet

Jenis mudharabah ini merupakan simpanan khusus dimana pemilik dana dapat menetapkan syarat-sayarat tertentu yang harus dipatuhi oleh bank.

2) Al-Mudharabah Muqayyadah off Balance Sheet

Jenis mudharabah ini merupakan penyaluran dana mudharabah langsung kepada pelaksana usahanya, dimana bank bertindak sebagai perantara yang mempertemukan antara pemilik dana dengan pelaksana usahanya.

Penyaluran Dana Bank Syariah (Pembiayaan)

Penyaluran Dana Bank Syariah
(Pembiayaan)

Menurut Sudarsono (2003:70), penyaluran dana Bank Syariah dilakukan dengan berbagai metode, seperti jual beli, bagi hasil, pembiayaan, pinjaman, dan investasi khusus.

1) Transaksi pembiayaan yang ditujukan untuk memiliki barang berdasarkan prinsip jual beli (bai'), meliputi bai' al murabahah, bai' as-salam, dan bai' alistishna.

2) Transaksi pembiayaan yang ditujukan untuk mendapatkan jasa berdasarkan prinsip sewa (ijarah). Transaksi pembiayaan yang ditujukan untuk usaha kerjasama yang ditujukan guna mendapatkan sekaligus barang dan jasa dengan prinsip bagi hasil meliputi mudharabah dan musyarakah.

\section{Financial Inclusion (inklusi keuangan)}

Menurut Bank Indonesia (2014) Inklusi keuangan merupakan seluruh upaya untuk meningkatkan akses masyarakat terhadap jasa-jasa kevangan dengan cara menghilangkan segala bentuk hambatan baik yang bersifat harga maupun non harga.

\section{Dimensi Pengukuran Financial Inclusion}

Dimensi pengukuran yang digunakan Bank Indonesia (2014) untuk mengukur pengembangan keuangan inklusif adalah:

1. Dimensi Akses, digunakan untuk mengukur kemampuan penggunaan jasa kevangan formal. Indikator pengukuran dimensi akses adalah: Jumlah Kantor Bank yang dimiliki oleh perbankan atau jumlah ATM yang tersebar.

2. Dimensi Penggunaan, digunakan untuk mengukur kemampuan penggunaan aktual produk dan jasa keuangan. Indikator pengukuran dimensi penggunaan adalah: Jumlah Rekening Dana Pihak Ketiga (Deposito, Tabungan, Giro), dan jumlah Rekening Kredit.

3. Dimensi Kualitas, digunakan untuk mengetahui apakah ketersediaan atribut produk dan jasa keuangan telah memenuhi kebutuhan pelanggan.

\section{Pertumbuhan Ekonomi}

Perhitungan pendapatan nasional dengan pendekatan produksi di Indonesia dilakukan dengan menjumlahkan semua 
Kholifatunahdliyah, et al/Jurnal Ekonomi Syariah Teori dan Terapan Vol. 6 No. 7 Juli 2019: 1395-1409; VARIABEL EKONOMI MONETER YANG MEMPENGARUHI PERTUMBUHAN EKONOMI DAN FINANCIAL INCLUSION BANK SYARIAH DI INDONESIA PERIODE 2010-2017

sektor industri yang ada, sektor industri tersebut dikelompokkan menjadi 11 sektor atas dasar ISIC (international standard industrialclassification) yang meliputi :

1. Sektor primer yaitu :1. Sektor produksi pertanian, 2. Sektor produksi pertambangan dan penggalian

2. Sektor sekunder, adalah: 1.Sektor industri manufaktur, 2.Sektor produksi listrik, gas, dan air minum, 3. Sektor produksi bangunan

3. Sektor tersier, adalah : 1. Sektor produksi perdagangan, hotel, dan restoran, 2.Sektor produksi transportasi dan komunikasi,3.Sektor produksi bank dan lembaga keuangan lainnya, 4.Sektor produksi sewa rumah, 5. Sektor produksi jasa lainnya.

Menurut (Kunt, dan Klapper, 2013) terdapat hubungan yang positif signifikan antara negara yang memiliki pendapatan perkapita tinggi dengan financial inclusion perbankan. Sedangkan, untuk negara berpendapatan rendah akan sulit untuk mengakses financial inclusion.

\section{Nilai Tukar}

Menurut Todaro (2000:247) kurs atau nilai tukar adalah suatu tingkat, tarif, harga dimana Bank Sentral bersedia menukar mata vang dari suatu negara dengan mata vang dari negara-negara lain.

Pridayanti (2012) meneliti mengenai "Pengaruh Ekspor, Impor, Dan Nilai Tukar Terhadap Pertumbuhan Ekonomi Di Indonesia Periode 2002-2012," menunjukkan hasil yang sama dengan penelitian diatas yakni nilai tukar berpengaruh negatif signifikan terhadap pertumbuhan ekonomi.

\section{Jumlah uang beredar}

Sesuai dengan UU No. 3 Tahun 2004 tentang Bank Indonesia yang terdapat dalam buku Widayatsari (2012: 108), Bank Indonesia merupakan otoritas moneter yang mempunyai tugas menetapkan dan melaksanakan kebijakan moneter, antara lain dengan mengendalikan jumlah vang beredar.

Angandrowa (2008) meneliti mengenai "Analisis Pengaruh Aspek Moneter Dan Fiskal Terhadap Pertumbuhan Ekonomi Indonesia" dengan variabel jumlah vang beredar sebagai salah satu indikator kebijakan moneter. Hasil estimasi menunjukkan bahwa jumlah vang beredar berhubungan positif terhadap pertumbuhan ekonomi Indonesia.

\section{Hipotesis dan Model Analisis}

Berdasarkan rumusan masalah dan landasan teori, hipotesis dan model analisis dari penelitian ini adalah.

1. HI : Nilai tukar berpengaruh signifikan terhadap pertumbuhan ekonomi

2. Jumlah vang beredar berpengaruh signifikan terhadap pertumbuhan ekonomi

3. Pertumbuhan ekonomi berpengaruh signifikan terhadap financial inclusion perbankan syariah. 


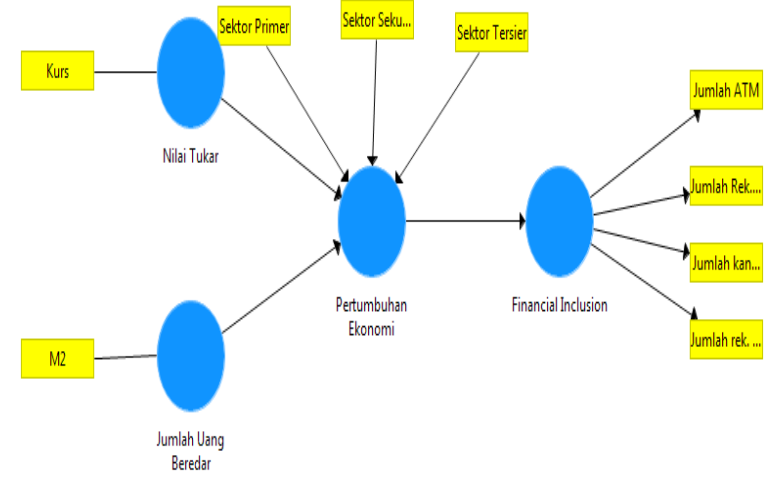

Sumber: SmartPLS 3.0

\section{Gambar 1.}

\section{Model Analisis}

III. METODE PENELITIAN

Pendekatan dalam penelitian ini adalah pendekatan kuantitatif. Variabel laten yang digunakan berjumlah empat variabel yaitu dua variabel eksogen (nilai tukar, dan jumlah uang beredar); satu variabel endogen intervening (pertumbuhan ekonomi); dan satu variabel endogen (financial inclusion). Adapun definisi operasional dalam penelitian ini ditunjukkan dalam tabel 1 berikut.

Tabel 1.

\section{Definisi Operasional}

\begin{tabular}{|c|c|c|}
\hline $\begin{array}{c}\text { Varia } \\
\text { bel }\end{array}$ & Indikator & Sumber Data \\
\hline Nilai Tukar & $\begin{array}{l}\text { Kurs Rupiah } \\
\text { terhadap dollar }\end{array}$ & $\begin{array}{c}\text { Bank } \\
\text { Indonesia, } \\
\text { Kementrian } \\
\text { perdagangan }\end{array}$ \\
\hline $\begin{array}{l}\text { Jumlah } \\
\text { Uang } \\
\text { Beredar }\end{array}$ & $\begin{array}{l}\text { Uang dalam arti } \\
\text { luas (M2) }\end{array}$ & $\begin{array}{c}\text { Bank } \\
\text { Indonesia, } \\
\text { Kementrian } \\
\text { perdagangan }\end{array}$ \\
\hline $\begin{array}{l}\text { Pertumbuha } \\
\text { n Ekonomi }\end{array}$ & $\begin{array}{l}\text { Sektor primer } \\
\text { Sektor sekunder } \\
\text { Sektor tersier }\end{array}$ & $\begin{array}{c}\text { Badan Pusat } \\
\text { Statistik }\end{array}$ \\
\hline $\begin{array}{l}\text { Financial } \\
\text { Inclusion }\end{array}$ & $\begin{array}{l}\text { Jumlah kantor } \\
\text { Jumlah rekening } \\
\text { DPK } \\
\text { Jumlah rekening } \\
\text { pembiayaan }\end{array}$ & $\begin{array}{c}\text { Statistik } \\
\text { Perbankan } \\
\text { Syariah OJK }\end{array}$ \\
\hline
\end{tabular}

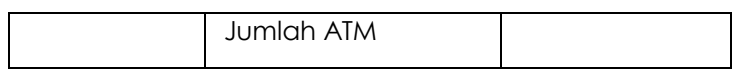

Sumber: Penulis

Jenis data yang digunakan dalam penelitian ini adalah data sekunder, berupa data yang dipublikasikan oleh lembaga yang berwenang seperti BPS, BI, dan OJK dalam kurun waktu 2010-2017 dengan sampel jenuh yakni Bank Syariah meliputi Bank Umum Syariah dan Unit Usaha Syariah. Oleh karena itu data untuk penelitian ini adalah data time series, yang melihat kinerja dari tahun ke tahun tanpa melihat perusahaannya.

Populasi dalam penelitian ini adalah (1) seluruh bank syariah di indonesia yang menjadi populasi dalam penelitian ini. Penelitian ini menggunakan teknik analisis Partial Least Square (PLS) untuk keperluan analisis data dan menggunakan software SmartPLS 3.0 sebagai alat bantu pengolahan data. Dalam PLS terdapat dua pengevaluasian model, yaitu evaluasi model pengukuran (outer model) dan evaluasi model struktural (inner model). Salah satu keunggulan PLS adalah dapat digunakan untuk menganalisis model dengan dukungan teori lemah, sehingga dapat menggunakan analogi dari bidang ilmu lain yang paling dekat hubungannya dengan model yang diteliti.

Konstruk yang digunakan dalam penelitian ini berbentuk formatif dan reflektif. Evaluasi model pengukuran digunakan untuk menguji kevalidan dari indikator yang membentuk konstruk. Chin dalam Ghozali, dan Latan (2014:76) menerangkan bahwa untuk mengevaluasi outer model yang 
Kholifatunahdliyah, et al/Jurnal Ekonomi Syariah Teori dan Terapan Vol. 6 No. 7 Juli 2019: 1395-1409; VARIABEL EKONOMI MONETER YANG MEMPENGARUHI PERTUMBUHAN EKONOMI DAN FINANCIAL INCLUSION BANK SYARIAH DI INDONESIA PERIODE 2010-2017

berbentuk formatif, dapat dilakukan melalui substantive content-nya yaitu dengan membandingkan besarnya relative weight dan melihat signifikansi t-statistik dari indikator konstruk tersebut melalui prosedur resampling. Oleh sebab itu uji validitas dan reliabilitas kontruk tidak diperlukan. Evaluasi model pengukuran (Outer Model) dengan konstruk berbentuk reflektif dalam PLS dapat dimulai dengan melihat nilai Indicator reliability yaitu besarnya variance dari indikator untuk menjelaskan konstruk laten dan composite reliability untuk mengukur reliabilitas konstruk secara keseluruhan (Ghozali, dan Hendri Latan, 2014:93-94).

Evaluasi model struktural bertujuan untuk memprediksi hubungan antar variabel laten yang dihipotesiskan (Ghozali, 2014:80). Secara lebih lanjutGhozali (2014:83) menjelaskan bahwa dalam menilai model struktural dengan PLS, akan dimulai dengan melihat nilai R-squares, kemudian nilai ${ }^{2}$ predictive relevancedanselanjutnya melihat nilai signifikansi t-statistik melalui prosedur bootstraping.

\section{HASIL DAN PEMBAHASAN}

\section{Evaluasi Model Pengukuran}

Evaluasi model pengukuran dalam PLS bertujuan untuk mengetahui apakah suatu indikator dikatakan valid untuk mengukur suatu variabel laten atau konstruknya. Hasil outer weight dalam penelitian ini dapat dilihat pada gambar 2 dibawah ini :

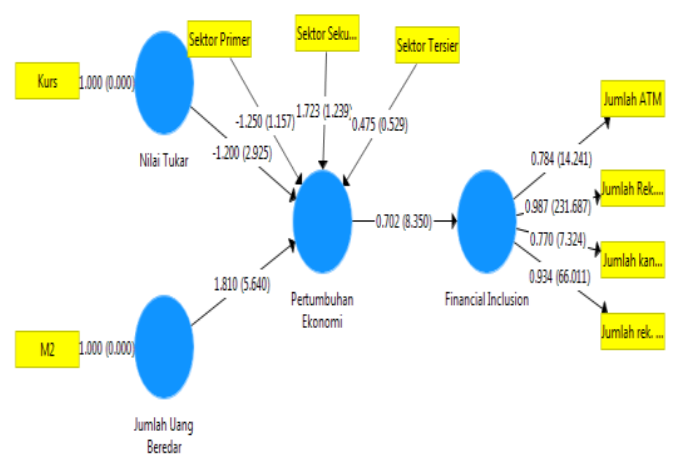

\section{Gambar 2.}

\section{Outer weight dan outer loadings}

Berdasarkan nilai outer weight pada Gambar 2, terdapat indikator yang tidak valid karena masing-masing memiliki nilai † statistik $<1,96$.

Chin dalam Ghozali(2014:76) menerangkan bahwa jika didapati nilai weight yang tidak signifikan maka hal ini akan menjadi masalah yang serius karena menghilangkan satu indikator formatif akan mengubah makna konstruk. Sebagai solusi, jika signifikan wight tidak signifikan akan tetapi nilai outer loading nya tinggi (>0.5) maka indikator tersebut tetap dipertahankan, sehingga tetap dipertahankan.

Berdasarkan uraian diatas, dapat disimpulkan bahwa seluruh indikator dikatakan valid untuk mengukur variabel laten peetumbuhan ekonomi serta financial inclusion karena memiliki outer loading >0,7.

\section{Evaluasi Model Struktural}

Model struktural bertujuan untuk memprediksi hubungan antar variabel laten yang dihipotesiskan. Evaluasi model struktural dalam PLS dapat melihat tiga nilai berikut, yaitu R-squares, $Q$-squares dan uji t. Berikut ini merupakan nilai $R$-squares dalam model yang diolah.

Tabel 2.

R-squares

\begin{tabular}{|l|c|}
\hline & $\begin{array}{c}\text { Original } \\
\text { Sample (O) }\end{array}$ \\
\hline $\begin{array}{l}\text { Pertumbuhan } \\
\text { ekonomi }\end{array}$ & 0,639 \\
\hline Financial inclusion & 0,492 \\
\hline
\end{tabular}


Kholifatunahdliyah, et al/Jurnal Ekonomi Syariah Teori dan Terapan Vol. 6 No. 7 Juli 2019: 1395-1409; VARIABEL EKONOMI MONETER YANG MEMPENGARUHI PERTUMBUHAN EKONOMI DAN FINANCIAL INCLUSION BANK SYARIAH DI INDONESIA PERIODE 2010-2017

Sumber: SmartPLS 3.0 (diolah)

Berdasarkan hasil tersebut dapat diketahui bahwa model pengaruh nilai tukar, dan jumlah uang beredar terhadap pertumbuhan ekonomi memiliki nilai $R$ squares 0,639. Hal ini menunjukkan bahwake-lima variabel tersebut dapat menjelaskan variabel pembiayaan bermasalah sebesar 63,9 persen, dan 36,1 persen dijelaskan oleh variabel lain diluar variabel yang telah diteliti Sementara itu, variabel fianancial inclusion yang dapat dijelaskan oleh pertumbuhan ekonomi 49,2 persen dan 50,8 persen dijelaskan oleh variabel lain. Berdasarkan hasil tersebut, dapat diasumsikan bahwa variabel endogen intervening pertumbuhan ekonomi memiliki model struktural yang kuat karena memiliki R-square antara $>0,45$ memasuki $\leq 0,70$ sedangkan variabel endogen financial inclusion memiliki model struktural (inner model) yang juga kuat karena R-squaresnya $>0,45$.

Untuk nilai Q-squaresdalam penelitian inididapat melalui perhitungan sebagai berikut:

$$
\begin{aligned}
& Q^{2}=1-\left[\left(1-R 1^{2}\right)\left(1-R 2^{2}\right) \ldots \ldots\left(1-R^{2}\right)\right] \\
& Q^{2}=1-\left(\left(1-0,492^{2}\right)(1-0,6392)\right) \\
& Q^{2}=1-((1-0,242064)(1-0,408321)) \\
& Q^{2}=1-((0,757936)(0,591679) \\
& Q^{2}=1-0,4484548145 \\
& Q^{2}=0,5515451855
\end{aligned}
$$

Berdasarkan perhitungan diatas dapat dilihat bahwa Q-squares sebesar 0,551, yakni $>0$, sehingga dapat disimpulkan bahwa model struktural tersebut mempunyai predictive relevance.
Langkah selanjutnya adalah uji pengaruh antar variabel atau uji signifikansi t. Penelitian ini menggunakan tingkat signifikansi sebesar 5\% dengan p-value 0,05. Jika diperoleh $p$-value $<0,05$ maka hipotesis diterima, begitupun sebaliknya. Pengujian hipotesis akan dilakukan dengan melihat hasil path coefficients yang dihasilkan melalui proses bootstraping, yang ditunjukkan pada tabel 4 berikut.

Tabel 3.

Path Coefficients

\begin{tabular}{|l|l|l|l|l|}
\hline & $\begin{array}{l}\text { Origin } \\
\text { al } \\
\text { Sampl } \\
\text { e (O) }\end{array}$ & $\begin{array}{l}\text { Standar } \\
\text { d } \\
\text { Deviatio } \\
\mathbf{n} \\
\text { (STDEV) }\end{array}$ & $\begin{array}{l}\text { T Statistics } \\
\text { (| O/STDEV } \\
\text { I) }\end{array}$ & $\begin{array}{l}\text { P } \\
\text { Value } \\
\text { S }\end{array}$ \\
\hline $\begin{array}{l}\text { Nilai tukar - } \\
>\end{array}$ & & & & \\
$\begin{array}{l}\text { Pertumbuh } \\
\text { an ekonomi }\end{array}$ & -1.200 & 0,386 & 3.113 & 0.002 \\
\hline $\begin{array}{l}\text { Jumlah } \\
\text { Uang } \\
\text { Beredar -> } \\
\text { Pertumbuh } \\
\text { an ekonomi }\end{array}$ & 1.810 & 0,307 & 5.896 & 0.000 \\
\hline $\begin{array}{l}\text { Pertumbuh } \\
\text { an ekonomi } \\
\text {-> Financial } \\
\text { inclusion }\end{array}$ & 0,702 & 0.081 & 8.702 & 0.000 \\
\hline
\end{tabular}

Sumber: SmartPLS 3.0 (diolah)

Berdasarkan tabel 3, dapat diinterpretasikan bahwa:

1. Terdapat pengaruh signifikan antara nilai tukar terhadap pertumbuhan ekonomi dengan $\mathrm{T}$ value 3.113 hal ini berarti $\mathrm{HI}$ diterima.

2. Terdapat pengaruh signifikan antara jumlah vang beredar terhadap pertumbuhan ekonomi dengan T value 5.896, hal ini berarti H2 diterima. 
3. Terdapat pengaruh signifikan antara pertumbuhan ekonomi terhadap financial inclusion dengan T value 8.702, hal ini berarti $\mathrm{H} 3$ diterima.

\section{Pembahasan}

\section{Pengaruh Nilai Tukar Terhadap Pertumbuhan} Ekonomi

Hasil analisis koefisien jalur (path coefficient) menunjukkan bahwa nilai tukar berpengaruh negatif signifikan terhadap pertumbuhan ekonomi dengan nilai $T$ statistik > T tabel yakni, 3,113> 1,96. Sedangkan $P$ value untuk nilai tukar terhadap pertumbuhan ekonomi adalah 0,02 atau kurang dari 0,05. Hal ini menunjukkan bahwa jika nilai tukar tinggi maka tingkat pertumbuhan ekonomi akan berkurang. Nilai koefisien parameter antara nilai tukar dan pertumbuhan ekonomi sebesar -1,200, hal tersebut menunjukkan jika nilai tukar bertambah 1 satuan, maka pertumbuhan ekonomi akan berkurang sebesar 1,200.

Nilai tukar yang mengalami kenaikan, jika dilihat dari sisi permintaan agregat dapat diasumsikan jika harga mata vang rupiah naik, sedangkan harga mata vang dollar tetap, maka dapat dipastikan kurs rupiah akan terdepresiasi. Hal tersebut manandakan nilai impor barang terjadi kenaikan, jika hal tersebut terjadi maka terjadi penurunan akan produksi barang dan jasa dalam negeri sehingga output yang diproduksi menurun dan akhirnya menurunkan pertumbuhan ekonomi.

Menurut Karim (2004:167-169), tidak terdapat perbedaan antara ilmu ekonomi islam dengan konvensional dalam hal faktor yang penyebab fluktuasi nilai tukar. Fluktuasi nilai tukar tetap disebabkan oleh faktor natural (permintaan dan penawaran agregat nilai tukar) dan human error. Emas dan perak adalah alat tukar yang sah dalam perniagaan pada zaman Rasulullah dan jarang terjadi inflasi. Inflasi terjadi ketika peperangan, dan human error karena korupsi dan kesalahan administrasi. Berikut adalah Hadits yang mengatur mengenai pertukaran emas dan perak dengan kadar yang sama :

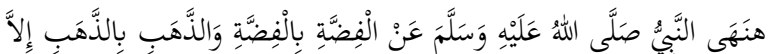

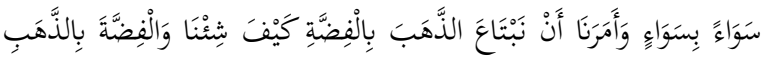
كَيْنَ شَيْنَا

Artinya: "Nabi SAW telah melarang menjual perak dengan perak dan emas dengan emas kecuali sama serta memerintahkan kami untuk membeli emas dengan perak sesuka kami dan (membeli) perak dengan emas sesuka kami."(HR al-Bukhari, Muslim, an-Nasa'i).

Hasil penelitian ini sesuai dengan beberapa penelitian yang telah dilakukan, diantaranya Pridayanti (2012) meneliti mengenai "Pengaruh Ekspor, Impor, Dan Nilai Tukar Terhadap Pertumbuhan Ekonomi Di Indonesia Periode 2002-2012," menunjukkan hasil yang sama dengan penelitian diatas yakni nilai tukar berpengaruh negatif signifikan terhadap pertumbuhan ekonomi.

Dari beberapa penelitian tersebut, penelitian ini mendukung penelitian yang dilakukan oleh Pridayanti (2012), yang 
Kholifatunahdliyah, et al/Jurnal Ekonomi Syariah Teori dan Terapan Vol. 6 No. 7 Juli 2019: 1395-1409; VARIABEL EKONOMI MONETER YANG MEMPENGARUHI PERTUMBUHAN EKONOMI DAN FINANCIAL INCLUSION BANK SYARIAH DI INDONESIA PERIODE 2010-2017

menyatakan bahwa nilai tukar berpengaruh negatif signifikan terhadap pertumbuhan ekonomi.

Pengaruh Jumlah Uang Beredar terhadap Pertumbuhan ekonomi

Hasil analisis koefisien jalur (path coefficient) menunjukkan bahwa jumlah uang beredar berpengaruh positif signifikan terhadap pertumbuhan ekonomi dengan nilai T statistik > T tabel yakni, 5,896> 1,96. Sedangkan $P$ value untuk inflasi terhadap pertumbuhan ekonomi adalah 0,00 atau kurang dari 0,05. Hal ini menunjukkan bahwa jika jumlah uang beredar tinggi maka tingkat pertumbuhan ekonomi akan meningkat. Nilai koefisien parameter antara jumlah uang beredar dan pertumbuhan ekonomi sebesar 1,810 hal tersebut menunjukkan jika tingkat inflasi bertambah 1 satuan, maka pertumbuhan ekonomi akan meningkat sebesar 1,810.

Menurut ilmu ekonomi konvensional, jumlah vang beredar dapat mempengaruhi besarnya inflasi yang ada pada pertumbuhan ekonomi. Jika jumlah uang beredar tinggi, dapat dipastikan inflasi juga tinggi. Hal tersebut sesuai dengan hipotesa Keynes, yakni penawaran uang (money supply) memiliki pengaruh positif terhadap output dan pertumbuhan ekonomi.

Alasan ilmu ekonomi konvensional diatas belum sesuai dengan ilmu ekonomi islam dikarenakan suku bunga menjadi alasan utamanya. Mazhab Alternatif erat kaitanya dengan konsep endogenous uang menyatakan bahwa nilai tambah akan uang adalah representasi dari perubahan dan pertambahan di sektor riil dalam hal ini adalah pertumbuhan ekonomi.

Menurut Chaudry (1997) dalam Karim (2006:191-192) menyatakan bahwa permintaan uang adalah cerminan dari keseluruhan kebutuhan transaksi dalam sekto riil. Permintaan dan penawaran uang dalam mazhab ini dipengaruhi oleh expected rate of profit atau profit sharing. Expected rate of profit merupakan harapan keuntungan yang didapatkan jika menginvestasikan uang pada sektor riil.

Apabila expected rate of profit meningkat, maka penawaran investasi meningkat. Tingginya penawaran investasi akan menyebabkan penurunan jumlah vang kas riil yang dipegang masyarakat karena menganggap memegang uang berlebih akan menghilangkan biaya kesempatan untuk mendapatkan keuntungan bisnis. Akibatnya, seseorang akan menyesuaikan seberapa besar permintaan uang kas riil yang dipegang terhadap besarnya expected rate of profit.

Keberadaan uang dalam sebuah perekonomian memberikan arti yang sangat penting. Ketidakadilan dari alat ukur yang diakibatkan adanya instabilitas nilai tukar vang, akan mengakibatkan perekonomian tidak berjalan pada titik keseimbangan. Pada zaman Rasulullah SAW penimbunan emas dan perak sangatlah dilarang. Sebagaimana dijelaskan pada Qs. AtTaubah:34 berikut ini :

34. Hai orang-orang yang beriman, Sesungguhnya sebahagian besar dari orang-orang alim Yahudi dan rahib-rahib 
Kholifatunahdliyah, et al/Jurnal Ekonomi Syariah Teori dan Terapan Vol. 6 No. 7 Juli 2019: 1395-1409; VARIABEL EKONOMI MONETER YANG MEMPENGARUHI PERTUMBUHAN EKONOMI DAN FINANCIAL INCLUSION BANK SYARIAH DI INDONESIA PERIODE 2010-2017

Nasrani benar-benar memakan harta orang dengan jalan batil dan mereka menghalang-halangi (manusia) dari jalan Allah. dan orang-orang yang menyimpan emas dan perak dan tidak menafkahkannya pada jalan Allah, Maka beritahukanlah kepada mereka, (bahwa mereka akan mendapat) siksa yang pedih,

Hasil penelitian ini sesuai dengan hasil penelitian yang dilakukan oleh Akapler, dan Duhok (2017), meneliti mengenai bagaimana kebijakan ekonomi dengan indikator jumlah uang beredar yakni money supply dapat berpengaruh terhadap pertumbuhan ekonomi, hasilnya menunjukkan bahwa jumlah uang beredar ternyata berpengaruh signifikan terhadap pertumbuhan ekonomi. Asongu (2014), meneliti mengenai pengaruh kebijakan moneter terhadap harga dan output jangka panjang maupun pendek di Afrika, hasilnya menunjukkan bahwa kebijakan moneter berupa money supply ternyata dapat meningkatkan output atau GDP.

Penelitian dengan hasil yang serupa dilakukan oleh Tambunan (2015) menganalisis "Pengaruh Jumlah Uang Beredar Dan Pengeluaran Pemerintah Terhadap Produk Domestik Bruto (Pdb) Indonesia," menunjukkan hasil bahwa † hitung dari variabel Jumlah Uang Beredar dengan taraf signifikan 95\% ( $=5 \%$ ) adalah 21,320 . Maka dengan demikian $†$ hitung $(21,320)>$ t tabel $(2,179)$ sehingga dapat disimpulkan bahwa variabel jumlah vang beredar berpengaruh positif secara signifikan terhadap Produk Domestik Bruto Indonesia.

Demikian dengan Santoso, dkk (2009) meneliti mengenai "Dampak Kebijakan Fiskal Dan Moneter Dalam Pertumbuhan ekonomi Indonesia: Aplikasi Model MundellFleming," dengan indikator inflasi sebagai salah satu pengukuran kebijakan moneter. Penelitian tersebut menunjukkan hasil bahwa Kebijakan moneter dalam bentuk pengaturan jumlah vang beredar ( permintaan vang) terbukti lebih signifikan dalam meningkatkan PDB dari sisi permintaan, dimana terdapat hubungan positif dan signifikan pada tingkat kepercayaan 1 persen antara variabel permintaan vang (M2) dan PDB dari sisi permintaan.

Dari beberapa penelitian diatas dapat disimpulkan bahwa penelitian ini sesuai dengan penelitian yang dilakukan Akapler, dan Duhok (2017), Asongu (2014), dan Santoso, dkk (2009) yang menyatakan bahwa jumlah vang beredar berpengeruh positif signifikan pada pertumbuhan ekonomi. Penelitian ini juga mendukung pendapat dari Chaudry (1997) dan hipotesa Keynes.

\section{Pengaruh pertumbuhan ekonomi terhadap}

\section{financial inclusion}

Hasil analisis koefisien jalur (path coefficient) menunjukkan bahwa pertumbuhan ekonomi berpengaruh positif signifikan terhadap pertumbuhan ekonomi dengan nilai T statistik > T tabel yakni, 8,702 $>1$ 1,96. Sedangkan $P$ value untuk inflasi terhadap pertumbuhan ekonomi adalah 
Kholifatunahdliyah, et al/Jurnal Ekonomi Syariah Teori dan Terapan Vol. 6 No. 7 Juli 2019: 1395-1409; VARIABEL EKONOMI MONETER YANG MEMPENGARUHI PERTUMBUHAN EKONOMI DAN FINANCIAL INCLUSION BANK SYARIAH DI INDONESIA PERIODE 2010-2017

0,00 atau kurang dari 0,022 . Hal ini menunjukkan bahwa jika pertumbuhan ekonomi tinggi maka financial inclusion akan meningkat. Nilai koefisien parameter antara pertumbuhan ekonomi dan financial inclusion sebesar 0,702 hal tersebut menunjukkan jika tingkat pertumbuhan ekonomi bertambah 1 satuan, maka financial inclusion akan meningkat sebesar 0,702 . Financial inclusion terbentuk melalui tiga indikator, yakni jumlah kantor, jumlah rekening DPK, jumlah rekening pembiayaan, dan jumlah ATM. Jumlah kantor memiliki nilai outer loading 0,770 jumlah rekening DPK sebesar 0,934 , jumlah rekening pembiayaan memiliki nilai outer loading sebesar 0,987, dan jumlah ATM memiliki outer loading 0,784.

Produk Domestik Bruto merupakan suatu indikator yang penting dalam mencerminkan pertumbuhan ekonomi suatu negara. Banyak faktor yang dapat mempengaruhi pertumbuhan ekonomi suatu negara, salah satunya yaitu pembangunan sektor keuangan.

Pertumbuhan ekonomi yang baik ditunjukkan oleh pertumbuhan PDB yang tinggi. Jika PDB mengalami pertumbuhan positif, dapat dipastikan arus kegiatan ekonomi telah berjalan sebagaimana mestinya, hal tersebut menunjukkan kondisi kesejahteraan suatu negara.

Pertumbuhan ekonomi yang baik akan mendorong masyarakat untuk dapat mengakses keuangan formal dikarenakan PDB yang tinggi menandakan pendapatan yang dimiliki masyarakat mengalami surplus sehingga perlu disalurkan pada bank yang akan menyalurkannya ke pihak defisit dana. Financial inclusion menunjukkan perluasan akses masyarakat terhadap melalui perbankan (Saputri,2016). Perluasan akses masyarakat terhadap sistem keuangan dilakukan agar dapat memperlancar perputaran dana disemua kalangan masyarakat. Hal ini sesuai dengan anjuran dalam islam QS. Al-Hasyr ayat 7 agar harta tidak hanya berputar pada satu kalangan saja :

7. apa saja harta rampasan (fai-i) yang diberikan Allah kepada RasulNya (dari harta benda) yang berasal dari penduduk kotakota Maka adalah untuk Allah, untuk rasul, kaum kerabat, anak-anak yatim, orangorang miskin dan orang-orang yang dalam perjalanan, supaya harta itu jangan beredar di antara orang-orang Kaya saja di antara kamu. apa yang diberikan Rasul kepadamu, Maka terimalah. dan apa yang dilarangnya bagimu, Maka tinggalkanlah. dan bertakwalah kepada Allah. Sesungguhnya Allah Amat keras hukumannya.

Penelitian ini tidak sesuai dengan Kunt, dan Klapper (2013) yang menyatakan bahwa terdapat hubungan yang positif signifikan antara negara yang memiliki pendapatan perkapita tinggi dengan financial inclusion perbankan. Sedangkan, untuk negara berpendapatan rendah akan sulit untuk mengakses financial inclusion.

Menurut (Kunt, dkk., 2013) menghasilkan penelitian bahwa nasabah muslim dan non muslim tidak memiliki perbedaan dalam mengakses keuangan formal. Hal yang membedakan adalah nasabah tersebut 
Kholifatunahdliyah, et al/Jurnal Ekonomi Syariah Teori dan Terapan Vol. 6 No. 7 Juli 2019: 1395-1409; VARIABEL EKONOMI MONETER YANG MEMPENGARUHI PERTUMBUHAN EKONOMI DAN FINANCIAL INCLUSION BANK SYARIAH DI INDONESIA PERIODE 2010-2017

banked atau unbanked (tidak memiliki pendapatan). Dalam hal ini baik nasabah muslim atau non muslim yang unbanked dipastikan tidak memiliki rekening formal yang artinya akan membuat rendahnya financial inclusion.

Pada penelitian ini, meskipun Indonesia adalah negara berkembang, pertumbuhan ekonomi justru berhubungan positif dengan financial inclusion. Hal tersebut menandakan bahwa Bank Syariah di Indonesia tidak memandang apakah masyarakat tersebut memiliki pendapatan (banked) atau tidak memiliki pendapatan (unbanked). Bank Syariah dapat dikatakan telah memberikan akses yang merata pada kalangan masyarakat baik masyarakat menengah ke bawah maupun menengah ke atas. Pertumbuhan ekonomi Indonesia sebagai negara berkembang yang medium jika dibandingkan dengan negara-negara di Asia Tenggara bahkan dunia yang telah maju telah menjadikan inklusifitas pada keuangan khususnya bank syariah. Alasan lain juga dapat diasumsikan bahwa pertumbuhan ekonomi di Indonesia menunjukkan tren positif sehingga dapat mendukung adanya akses keuangan formal yang dapat membangun inklusifitas Bank Syariah.

Penelitian ini tidak sesuai dengan pendapat Kunt, dan Klapper (2013) yang menyatakan bahwa terdapat hubungan yang positif signifikan antara negara yang memiliki pendapatan perkapita tinggi dengan financial inclusion perbankan. Negara berkembang yang memiliki pendapatan rata-rata, namun akses keuangan yang bagus dalam artian mudah diakses dan memiliki pelayanan keuangan yang merata juga dapat meningkatkan keuangan secara inklusif.

\section{SIMPULAN}

Berdasarkan analisis serta pengujian hipotesis yang telah diuraikan, maka dapat ditarik kesimpulan sebagai berikut:

1. Hasil analisis koefisien jalur (path coefficient) menunjukkan bahwa nilai tukar berpengaruh negatif signifikan terhadap pertumbuhan ekonomi dengan nilai T statistik > T tabel yakni, $3,113>1,96$. Sedangkan $P$ value untuk inflasi terhadap pertumbuhan ekonomi adalah 0,02 , atau kurang dari 0,05 . Hal ini menunjukkan bahwa jika nilai tukar tinggi maka tingkat pertumbuhan ekonomi akan berkurang. Nilai koefisien parameter antara nilai tukar dan pertumbuhan ekonomi sebesar -1,200, hal tersebut menunjukkan jika tingkat inflasi bertambah 1 satuan, maka pertumbuhan ekonomi akan berkurang sebesar 1,200. Nilai tukar berpengaruh negatif signifikan dikarenakan nilai tukar yang meningkat (terdepresiasi) menunjukkan impor yang terlalu tinggi sehingga membuat output menjadi berkurang.

2. Hasil analisis koefisien jalur (path coefficient) menunjukkan bahwa jumlah vang beredar berpengaruh positif signifikan terhadap pertumbuhan ekonomi dengan nilai T statistik > T tabel yakni, 5,896 > 1,96. Sedangkan $P$ value 
Kholifatunahdliyah, et al/Jurnal Ekonomi Syariah Teori dan Terapan Vol. 6 No. 7 Juli 2019: 1395-1409;

VARIABEL EKONOMI MONETER YANG MEMPENGARUHI PERTUMBUHAN EKONOMI DAN FINANCIAL INCLUSION BANK SYARIAH DI INDONESIA PERIODE 2010-2017

untuk inflasi terhadap pertumbuhan ekonomi adalah 0,00 atau kurang dari 0,05. Hal ini menunjukkan bahwa jika jumlah uang beredar tinggi maka tingkat pertumbuhan ekonomi akan meningkat. Nilai koefisien parameter antara inflasi dan pertumbuhan ekonomi sebesar 1,810 hal tersebut menunjukkan jika tingkat inflasi bertambah 1 satuan, maka pertumbuhan ekonomi akan meningkat sebesar 1,810. Jumlah vang beredar berpengaruh positif signifikan terhadap pertumbuhan ekonomi karena jumlah vang beredar sebenarnya merefleksikan pertumbuhan ekonomi suatu negara. Jumlah vang beredar berpengaruh positif signifikan terhadap pertumbuhan ekonomi dikarenakakan jika jumlah vang beredar naik, maka Bl akan menaikkan jumlah vang beredar yang nantinya akan menurunkan jumlah vang beredar. Jumlah uang beredar yang rendah menunjukkan inflasi yang rendah. Hal tersebut akan mendorong masyarakat untuk melakukan investasi sehingga akan menaikkan pertumbuhan ekonomi.

3. Hasil analisis koefisien jalur (path coefficient) menunjukkan bahwa pertumbuhan ekonomi berpengaruh positif signifikan terhadap financial inclusion dengan nilai T statistik $>T$ tabel yakni, 8,702 > 1,96. Sedangkan $P$ value untuk inflasi terhadap pertumbuhan ekonomi adalah 0,00 atau kurang dari 0,05. Hal ini menunjukkan bahwa jika pertumbuhan ekonomi tinggi maka financial inclusion akan meningkat. Nilai koefisien parameter antara pertumbuhan ekonomi dan financial inclusion sebesar 0,702 hal tersebut menunjukkan jika tingkat pertumbuhan ekonomi bertambah 1 satuan, maka financial inclusion akan meningkat sebesar 0,702. Financial inclusion terbentuk melalui empat indikator, yakni jumlah kantor, jumlah rekening DPK, dan jumlah rekening pembiayaan. Jumlah kantor memiliki nilai outer loading 0,770, jumlah rekening DPK sebesar 0,934,jumlah rekening pembiayaan memiliki nilai outer loading sebesar 0,987, dan jumlah ATM sebesar 0,784. Pertumbuhan ekonomi berpengaruh positif signifikan terhadap financial inclusion dikarenakan jika output yang dihasilkan masyarakat meningkat, maka kondisi kesejahteraan telah terjadi. Jika masyarakat telah memiliki pendapatan yang tinggi, maka masyarakat akan memiliki minat untuk mengakses keuangan formal dalam hal ini financial inclusion.

\section{DAFTAR PUSTAKA}

Ayunia, Pridayanti.2012. Pengaruh Ekspor, Impor, Dan Nilai Tukar Terhadap Pertumbuhan Ekonomi Di Indonesia Periode 2002-2012. Surabaya : Universitas Negeri Surabaya.

Demirguc-Kunt Dan Leora Klapper. 2013 Measuring Financial Inclusion. Jel Codes: G2, G21, O16, World Bank.

Departemen Agama RI. 2004. Al-Quran dan Terjemahnya. Bandung: CV Penerbit J-Art. 
Kholifatunahdliyah, et al/Jurnal Ekonomi Syariah Teori dan Terapan Vol. 6 No. 7 Juli 2019: 1395-1409;

VARIABEL EKONOMI MONETER YANG MEMPENGARUHI PERTUMBUHAN EKONOMI DAN FINANCIAL INCLUSION BANK SYARIAH DI INDONESIA PERIODE 2010-2017

Ergin Akalpler, Dilgash Duhok. 2017. Does Monetary Policy Affect Economic Growth: Evidence From Malaysia. Journal Of Economic And Administrative Sciences. Vol. 34 Issue: 1, Pp.2-20, Emerald Insight.

Ghozali, Imam. 2014. Partial Least Squares: Konsep dan Aplikasi Path Modeling Menggunakan Program XLSTAT-PLS. Semarang: Badan Penerbit Universitas Diponegoro.

Gulo, Angandrowa. 2008. Analisis Pengaruh Aspek Fiskal Dan Moneter Terhadap Pertumbuhan ekonomi Indonesia. Visi (2008) 16 (3) 595 - 611, Issn 0853 0203

Karim, Adiwarman.2004. Bank Islam Analisis Figh Dan Kevangan. Jakarta: Raja Grafindo Persada.

Santoso, Teguh,Dkk., 2009. Dampak Kebijakan Fiskal Dan Moneter Dalam Perekonomian Indonesia: Aplikasi Model Mundell-Fleming. Jurnal Organisasi Dan Manajemen, Volume 5, Nomor 2, September 2009, 108-128.

Shihab, M. Quraish. 2009. Tafsir Al-Mishab:

Pesan, Kesan, dan Keserasian AlQuran. Jakarta: Lentera Hati.

Sudarsono, heri.2003. Bank dan lembaga keuangan syariah Deskripsi dan ilustrasi. Yogyakarta : Ekonisia.

Tambunan, Sely Nory. 2015. Pengaruh Jumlah Uang Beredar Dan Pengelvaran Pemerintah Terhadap Produk Domestik Bruto (Pdb) Indonesia. Jom Fekon Volume 2 No. 1 Februari 2015
Todaro, Michael P. 2006. Pembangunan Ekonomi di Dunia Ketiga. Jakarta: Erlangga.

Widayatsari.2012. Ekonomi Moneter II. Pekanbaru:Cendika Insani

Wiroso.2011. Produk Perbankan Syariah. Jakarta : Lppe Usakti

www.Worldbank.Org, Diakses Tanggal 20 November

www.Bps.Go.Id, Diakses Tanggal 20 November 2017.

www.Bi.Go.Id, Diakses Tanggal 20 November 2017. 